\title{
ESTUDO DA PENETRAÇÃO DE CLORETOS EM CONCRETOS EXPOSTOS POR DOIS ANOS EM AMBIENTE MARINHO
}

\author{
A. MEDEIROS, L. Y. CHEEN, B. GENEROSO, \\ T. B. ABRAHÃO, G. C. SILVEIRA, W. MAZER \\ DACOC, Engenharia Civil, Universidade Tecnológica Federal do Paraná, Curitiba, Brazil.
}

\begin{abstract}
RESUMO
A penetração de cloretos no concreto armado é uma das principais causas de corrosão nas armaduras e consequente deterioração das estruturas de concreto. O ambiente marinho é uma das principais fontes de íons cloreto que deteriora estruturas de concreto, seja pela névoa salina ou por respingos de maré. A costa brasileira tem mais de $9.000 \mathrm{~km}$ e tem centenas de cidades com construções muito próximas ao mar que sofrem com corrosão de armaduras pela penetração de íons cloreto. Atualmente, os códigos de projeto brasileiros consideram o ambiente marinho como uma mesma região com os mesmos critérios de projeto para o cobrimento das armaduras. Neste contexto, este estudo avalia a penetração de cloretos em corpos de prova prismáticos de concreto armado de $30 \mathrm{MPa}$, que foram deixados em exposição natural por mais de 2 anos, em diferentes condições de exposição interna e externa a uma edificação em frente ao mar, uma edificação localizada a $700 \mathrm{~m}$ do mar, na margem de uma lagoa a $200 \mathrm{~m}$ do mar e também em uma região de respingos de maré em rochas que estão dentro do mar, na cidade de Barra Velha, no estado de Santa Catarina, no Sul do Brasil. Foram coletadas amostras dos concretos em até $10 \mathrm{~mm}$ de profundidade para estimar pelo método de Volhard a quantidade de cloretos que penetrou nos concretos em 7 diferentes locais de exposição próximos ao mar. Os concretos expostos externos à edificação e mais próximos do mar foram os que tiveram os teores de penetração de cloretos mais elevados em até $3 \mathrm{x}$ mais quando comparados aos que ficaram expostos internos à edificação e distantes do mar. Estes corpos de prova continuam expostos nos mesmos locais para futuras avaliações da penetração de cloretos. Palavras clave: concreto armado; deterioração; cloreto; corrosão; ambiente marinho.
\end{abstract}

\begin{abstract}
The penetration of chlorides in reinforced concrete is one of the main causes of corrosion in the reinforcement and consequent deterioration of concrete structures. The marine environment is one of the major sources of chloride ions that deteriorates concrete structures, either by saline mist or by tidal splashes. The Brazilian coast has more than 9,000 km and has hundreds of cities with buildings very close to the sea that suffer with corrosion by the penetration of chloride ions. Currently, the Brazilian design codes consider the marine environment as the same region with the same design criteria for the covering of the reinforcements. In this context, this study evaluates the penetration of chlorides in prismatic reinforced concrete specimens of $30 \mathrm{MPa}$, which were left in natural exposure for more than 2 years, in different conditions of internal and external exposure to a building in front of the sea, a building located $700 \mathrm{~m}$ from the sea, on the shore of a lagoon $200 \mathrm{~m}$ from the sea and also in a region of tidal splashes in rocks that are in the sea, in the city of Barra Velha, in the state of Santa Catarina, in the South of Brazil. Samples of the concretes were collected up to $10 \mathrm{~mm}$ deep to estimate by the Volhard method the amount of chlorides that penetrated the concrete at 7 different exposure sites near the sea. The concretes exposed outside the building and closer to the sea were those that had the highest penetration levels of chlorides up to $3 \mathrm{x}$ more when compared to those that were exposed internal to the building and distant from the sea. These specimens continue to be exposed at the same sites for future assessments of chloride penetration. Keywords: reinforced concrete; deterioration; chlorides; corrosion; marine environment.
\end{abstract}




\section{INTRODUÇÃO}

O concreto armado é a opção estrutural de maior utilização na construção civil e pode-se verificar que a corrosão de armaduras é o dano mais frequente; o recordista em número de ocorrência de patologias (Guilherme Silva, 1994). A deterioração das armaduras do concreto ocorre por diversos fatores, como a oxidação, carbonatação e ataque de cloretos, sendo a última o enfoque da pesquisa. Essa corrosão afeta de maneira desfavorável a estrutura, podendo comprometer a durabilidade da estrutura.

No mundo existem diversos trabalhos a respeito da quantificação dos cloretos nas armaduras do concreto, mas em quase sua totalidade esses estudos são referentes a sistemas criados em laboratórios. Nestes casos, procura-se simular o ambiente real onde são utilizadas maneiras de acelerar a contaminação, ficando suscetível a erros, devido a enorme diversidade de eventos que podem sobrevir na realidade. Em contrapartida está pesquisa baseou-se em amostras expostas à ambientes reais para mensurar a porção de cloretos presente nas armaduras, de maneira a encontrar veracidade nos resultados.

O íon cloreto é encontrado essencialmente em regiões costeiras, tanques de tratamento de água, piscinas e áreas industriais. Portanto, foi escolhido um ambiente marinho para a realização do estudo, devido à vulnerabilidade nesta área.

\subsection{Exposição}

Para maior compreensão do assunto é necessário conhecer as maneiras que o íon cloreto é conduzido para o interior do material. Existem quatro mecanismos de transporte de íons no concreto: Absorção Capilar, Permeabilidade, Difusão e Migração Iônica, que podem atuar simultaneamente ou sucessivamente ao longo do tempo, conforme as condições de exposição às quais o concreto se encontra submetido (Luciana Calçada, 2004 apud Aline Troian, 2010) Na tabela 1 são apresentadas as diferentes classes de agressividade ambiental para estruturas de concreto armado, definidas por norma no Brasil, onde aconteceu esta pesquisa, pela ABNT NBR 6118 (2014).

Tabela 1: Classe de agressividade ambiental

\begin{tabular}{|c|c|c|c|}
\hline $\begin{array}{c}\text { Classe de } \\
\text { agressividade } \\
\text { ambiental } \\
\end{array}$ & Agressividade & $\begin{array}{l}\text { Classificação Geral do tipo de } \\
\text { ambiente para efeito de projeto }\end{array}$ & $\begin{array}{c}\text { Risco de } \\
\text { deterioração da } \\
\text { estrutura } \\
\end{array}$ \\
\hline \multirow{2}{*}{ I } & \multirow{2}{*}{ Fraca } & Rural & \multirow{2}{*}{ Insignificantes } \\
\hline & & Submersa & \\
\hline II & Moderada & Urbana a,b & Pequeno \\
\hline \multirow{2}{*}{ III } & \multirow{2}{*}{ Forte } & Marinha a & \multirow{2}{*}{ Grande } \\
\hline & & Industrial $\mathrm{a}, \mathrm{b}$ & \\
\hline \multirow{2}{*}{ IV } & \multirow{2}{*}{ Muito Forte } & Industrial a,c & \multirow{2}{*}{ Elevado } \\
\hline & & Respingos de Maré & \\
\hline \multicolumn{4}{|c|}{$\begin{array}{l}\text { a Pode-se admitir um microclima com uma classe de agressividade mais branda (uma classe acima) } \\
\text { para ambientes internos secos (salas, dormitórios, banheiros, cozinhas e áreas de serviço de } \\
\text { apartamentos residenciais e conjuntos comerciais ou ambientes com concreto revestido com } \\
\text { argamassa e pintura). } \\
\text { b Pode-se admitir uma classe de agressividade mais branda (uma classe acima) em obras em regiões } \\
\text { de clima seco, com umidade média relativa do ar menor ou igual a } 65 \% \text {, partes da estrutura protegidas } \\
\text { de chuva em ambientes predominante secos ou regiões onde raramente chove. } \\
{ }^{c} \text { Ambientes quimicamente agressivos, tanques industriais, galvanoplastia, branqueamento em } \\
\text { indústrias de celulose e papel, armazéns de fertilizantes, indústrias químicas. }\end{array}$} \\
\hline
\end{tabular}


Portanto, existem diversas situações que levam a contaminação de cloretos, que pode ocorrer por meio de agentes externos ou internos, no qual o primeiro acontece por um ataque à superfície do concreto, podendo variar de acordo com o local exposto, enquanto o segundo acontece no momento de preparo da estrutura, conforme a tabela 2 (Paulo Helene, 1993).

Tabela 2: Maneiras de contaminação

\begin{tabular}{|c|c|}
\hline Fontes externas & $\begin{array}{l}\text { Incorporados à massa } \\
\text { de concreto }\end{array}$ \\
\hline Maresia ou névoa de ambiente marinho & \multirow{2}{*}{$\begin{array}{c}\text { Aditivos aceleradores } \\
\text { de pega }\end{array}$} \\
\hline Água do mar (zonas de respingo e variação de maré) & \\
\hline Sais de degelo & \multirow{2}{*}{$\begin{array}{c}\text { Água de amassamento } \\
\text { contaminada }\end{array}$} \\
\hline Processos industriais & \\
\hline Solos contaminados & \multirow{2}{*}{$\begin{array}{l}\text { Agregados } \\
\text { contaminados }\end{array}$} \\
\hline Lavagens com ácido muriático & \\
\hline
\end{tabular}

\subsection{Mecanismo de ataque}

$\mathrm{O}$ ataque de cloretos é causado preferencialmente de duas maneiras, pela reação com o cloreto de sódio $(\mathrm{NaCl})$ ou com o cloreto de magnésio $\left(\mathrm{MgCl}_{2}\right)$, sendo a primeira ocorre por meio do consumo dos íons de cálcio da portlandita e do C-S-H e a possível transformação em etringita, assim ocorre o aumento da porosidade do concreto facilitando a intrusão do íons de cloreto $\left(\mathrm{Cl}^{-}\right)$nas armaduras (Escadeillas e Hornain, 2014), conforme as equações (1)-(2). Na segunda maneira, verifica-se a precipitação de brucita insolúvel ou a formação de C-M-S-H, sem propriedades ligantes, equações (3)-(4), deixando os aços vulneráveis à corrosão, ainda, ocasiona a absorção da umidade atmosférica, deixando a superfície do metal sempre umedecida e, consequentemente, sujeita à corrosão, devido à presença de eletrólitos fortes $\left(\mathrm{NaCl}\right.$ e $\left.\mathrm{MgCl}_{2}\right)$ e água (Gentil, 2007).

$$
\begin{aligned}
& \mathrm{Ca}(\mathrm{OH})_{2}+2 \mathrm{NaCl} \leftrightarrow \mathrm{CaCl}_{2}+2 \mathrm{NaOH} \\
& \mathrm{C}-\mathrm{S}-\mathrm{H}+2 \mathrm{NaCl} \rightarrow \mathrm{CaCl}_{2}+2 \mathrm{NaOH}+\text { sílica } \\
& \mathrm{Ca}(\mathrm{OH})_{2}+\mathrm{MgCl}_{2} \rightarrow \mathrm{CaCl}_{2}+\mathrm{Mg}(\mathrm{OH})_{2} \\
& \mathrm{C}-\mathrm{S}-\mathrm{H}+\mathrm{MgCl}_{2} \rightarrow \mathrm{CaCl}_{2}+\mathrm{C}-\mathrm{M}-\mathrm{S}-\mathrm{H}
\end{aligned}
$$

De acordo com Paulo Helene (1999) apud Daniel Ribeiro (2010), os ânions $\mathrm{Cl}^{-}$, podem reagir com o ferro sem ser consumido, causando uma aceleração permanente no processo de corrosão do aço, em virtude de o cloreto retornar em forma livre, figura 1, ao final da reação, conforme as equações (5)-(6).

$$
\begin{aligned}
& \mathrm{Fe}^{3+}+3 \mathrm{Cl}^{-} \rightarrow \mathrm{FeCl}_{3}+\mathrm{H}_{2} \mathrm{O} \\
& \mathrm{FeCl}_{3}+3 \mathrm{OH}^{-} \rightarrow 3 \mathrm{Cl}^{-}+\mathrm{Fe}(\mathrm{OH})_{3}
\end{aligned}
$$




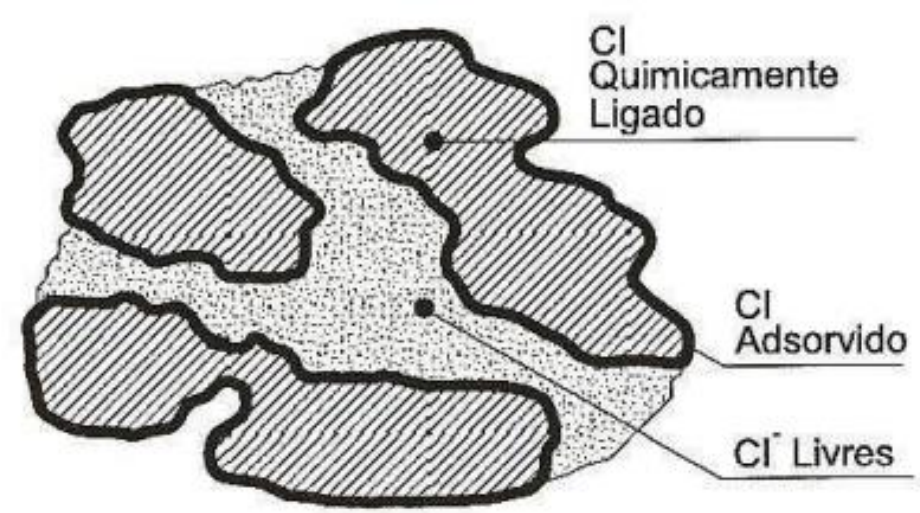

Figura 1: Íons cloro no concreto

\section{PROCEDIMENTO}

\subsection{Produção das vigas}

Foram confeccionados corpos de prova prismáticos com dimensões $15 \times 15 \times 50 \mathrm{~cm}$, armadura principal de $10 \mathrm{~mm}$ de diâmetro, cinco estribos de $5 \mathrm{~mm}$ de diâmetro, conforme a figura 2, e cobrimento de 30 $\mathrm{mm}$.

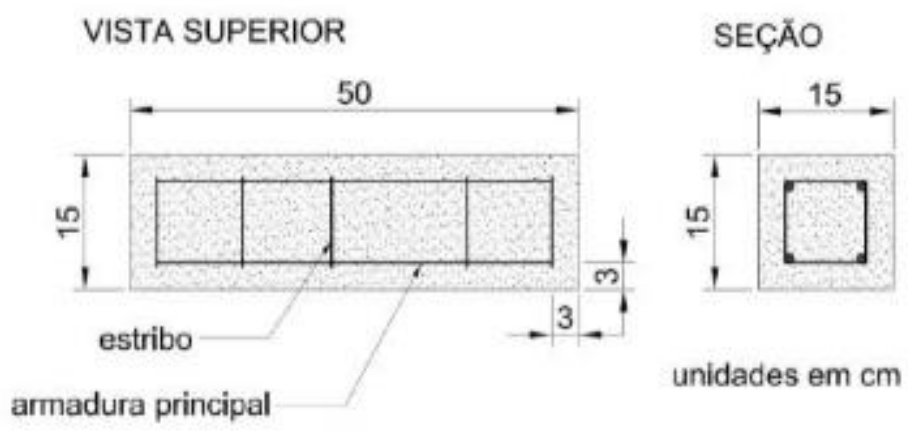

Figura 2: Viga produzida

Produziu-se um concreto com resistência característica a compressão à axial de $30 \mathrm{MPa}(\mathrm{C} 30)$, com consumo de materiais descrito na tabela 3 .

Tabela 3: Traço do concreto

\begin{tabular}{|c|c|c|c|c|c|}
\cline { 2 - 6 } \multicolumn{1}{c|}{} & CP II-F & $\begin{array}{c}\text { Areia } \\
\text { Natural }\end{array}$ & $\begin{array}{c}\text { Areia } \\
\text { Artificial }\end{array}$ & Brita 1 & Água \\
\hline Consumo (kg) & 280 & 492 & 492 & 926 & 195 \\
Traço & 1,00 & 1,76 & 1,76 & 3,31 & 0,70 \\
\hline
\end{tabular}

\subsection{Ambiente de exposição}

Os corpos de prova foram distribuídos pelas cidades de Barra Velha e Curitiba, nos estados de Santa Catarina (SC) e Paraná (PR) respectivamente, devido à facilidade de exposição em diversas locais internos e externos. Foram expostas várias vigas ao ambiente real, para se obter uma maior quantidade de amostras, dentre estas foram selecionadas oito vigas, sendo sete de SC e uma do PR, seguindo a seguinte distribuição, auxiliada na tabela (4) e figura (3): 
- Uma viga (identificada V1) C30, no prédio da UTFPR-CT, em Curitiba, classe de agressividade 1, utilizada como referência, sem contaminação de cloretos;

- Uma viga (V2) C30, em um píer de uma lagoa, classe de agressividade 3, a aproximadamente 350 metros do mar, figura (3);

- Uma viga (V3) C30, na laje do primeiro pavimento e exposição direta ao mar, classe de agressividade 3, a aproximadamente 60 metros do mar;

- Uma viga (V4) C30, em zona de respigo de maré, classe de agressividade 4, em um rochedo adentrando o mar;

- Duas vigas (V5 e V6) C30, respectivamente na entrada e no fundo de uma garagem fechada, classe de agressividade 3, a aproximadamente 50 metros do mar;

- Uma viga (V7) C30, na varanda, fechada com janelas, do apartamento no $5^{\circ}$ andar, classe de agressividade 3, a uma distância direta de aproximadamente 160 metros do mar;

- Uma viga (V8) C30, na garagem de uma residência, classe de agressividade 2, a aproximadamente 820 metros do mar.

Tabela 4: Identificação dos corpos de prova

\begin{tabular}{|c|c|c|}
\hline Numeração & Local & Localização no mapa \\
\hline V1 & Referência & - \\
\hline V2 & Lagoa & 3 \\
\hline V3 & Laje & $1\left(1^{\circ}\right.$ andar $)$ \\
\hline V4 & Praia & 2 \\
\hline V5 & Garagem (portão) & 1 (Térreo) \\
\hline V6 & Garagem (fundo) & 1 (Térreo) \\
\hline V7 & Apartamento & 1 ( $^{\circ}$ andar $)$ \\
\hline V8 & Garagem casa térrea & 4 \\
\hline
\end{tabular}

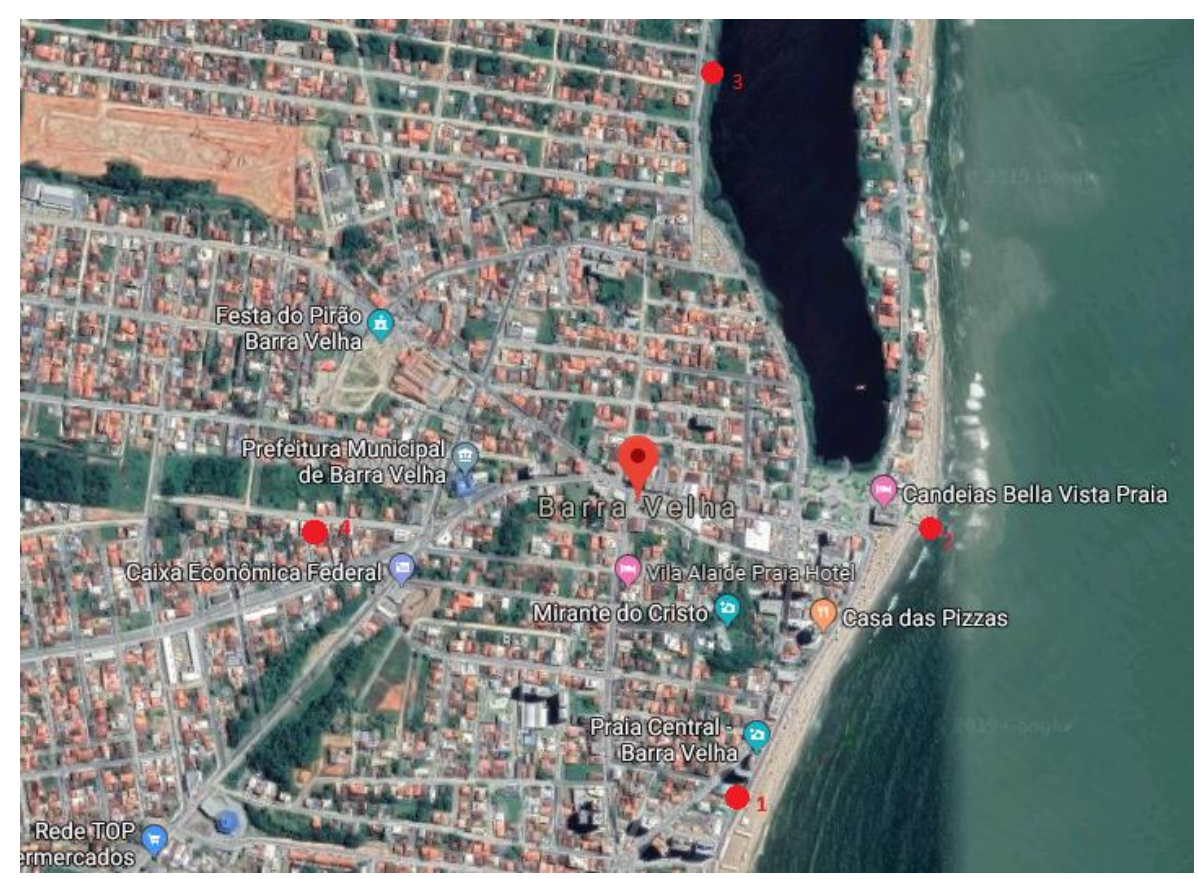

Figura (3): Localização dos corpos de prova

Fonte: Adaptação Google Maps 


\subsection{Método de Volhard}

O método descrito por Andrade (1992), pode ser utilizado para determinar cloretos livres e totais, mudando apenas a preparação inicial. Nesse estudo se optou por utilizar um peso reduzido utilizando 5 gramas de concreto, ao invés de 20 gramas como previsto no método.

Para medir a quantidade de cloretos nas estruturas, é necessário o recolhimento de amostras na forma de pó, devido a sua dissolução em meio ácido ocasionar a liberação dos cloretos livres presentes na estrutura. A extração deste pó foi realizada com a utilização de uma furadeira, realizando furos de no máximo $10 \mathrm{~mm}$ de profundidade, em sequência, a amostra é peneirada a fim de retirar as impurezas. $O$ procedimento segue uma série de passos que serão descritos resumidamente:

1. Misturar a amostra com $50 \mathrm{ml}$ de água deionizada e $10 \mathrm{ml}$ de Ácido Nítrico $(65 \%)$ em um frasco Erlenmeyer (200ml);

2. Aquecer a solução em um agitador magnético até a ebulição;

3. Após atingir a temperatura de equilíbrio, filtrar em um filtro de papel de filtragem média;

4. Adicionar ao filtrado $10 \mathrm{ml}$ de Ácido Nítrico $(65 \%)$ e Nitrato de Prata $(0,05 \mathrm{~N})$ até começar precipitar os cristais e mais $5 \mathrm{ml} \mathrm{em}$ excesso;

5. Aquecer novamente a solução até a ebulição para que ocorra a coagulação do Cloreto de Prata;

6. Depois de esfriar a solução, adicionar $10 \mathrm{ml}$ de Álcool Benzílico e deixar misturar no agitador magnético por 2 minutos;

7. Misturar $10 \mathrm{ml}$ de Sulfato de Amônia e Ferro (III);

8. Com o auxílio de uma bureta, adicionar de 0,2 em 0,2 $\mathrm{ml}$ Tiocianato de Amônia até atingir a tonalidade da figura 4

9. Por fim, com os dados obtidos utilizando a equação 7, de acordo com Andrade (1992).

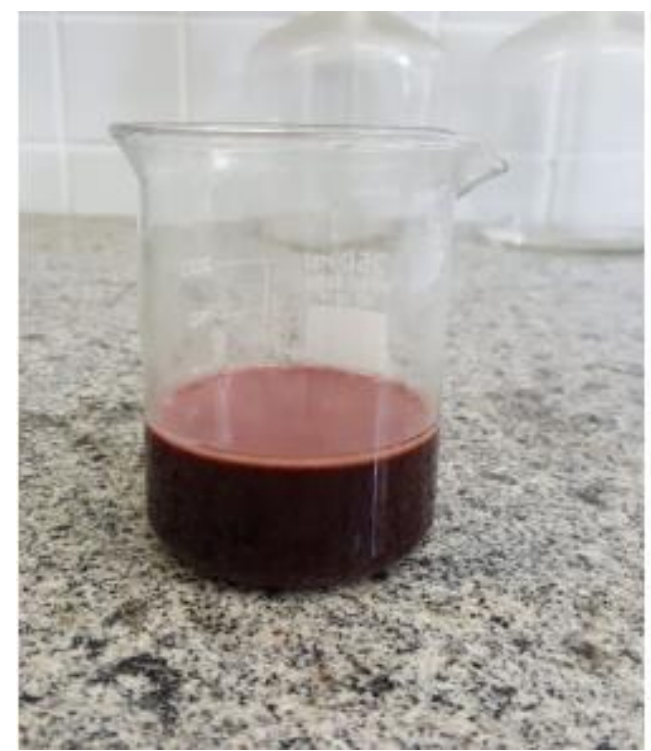

Figura 4. Tonalidade obtida no método

$$
C l \%=\frac{0,1773 *(V 1-V 2)}{W}
$$

- $\mathrm{Cl} \%$ é a concentração de cloretos da amostra, em porcentagem;

- $\mathrm{V}_{1}$ é o volume de Tiocianato de Amônia da amostra (ml);

- V $\mathrm{V}_{2}$ é o volume de Tiocianato de Amônia da amostra "branca" (ml);

- W é a massa da amostra de concreto (g) - (em todas as amostras usou-se 5g). 


\section{RESULTADOS}

Apesar da adoção de medidas tomada a fim de evitar o deslocamento da posição inicial dos corpos de prova, não foi possível mantê-los no local inicial, sendo assim foi utilizada a face de maior exposição para realizar os testes. A tabela 5 apresenta os dados recolhidos da quantidade de Tiocianato de Amônia utilizado em cada corpo de prova.

Tabela 5: Volume de Tiocianato de Amônia

\begin{tabular}{|c|c|c|c|c|c|}
\hline Numeração & $\begin{array}{c}\text { Amostra 1 } \\
(\mathbf{m l})\end{array}$ & $\begin{array}{c}\text { Amostra 2 } \\
(\mathbf{m l})\end{array}$ & $\begin{array}{c}\text { Amostra 3 } \\
(\mathbf{m l})\end{array}$ & $\begin{array}{c}\text { Amostra 4 } \\
(\mathbf{m l})\end{array}$ & Média (ml) \\
\hline V1 & 0,21 & 0,17 & $\mathrm{x}$ & $\mathrm{X}$ & 0,190 \\
\hline V2 & 0,95 & $\mathrm{X}$ & 0,7 & 0,85 & 0,833 \\
\hline V3 & 0,89 & 0,9 & 0,74 & 0,66 & 0,798 \\
\hline V4 & 0,75 & 0,7 & 0,7 & 0,72 & 0,718 \\
\hline V5 & 0,3 & 0,33 & $\mathrm{x}$ & $\mathrm{X}$ & 0,315 \\
\hline V6 & 0,27 & 0,29 & $\mathrm{x}$ & $\mathrm{X}$ & 0,280 \\
\hline V7 & 0,72 & 0,9 & 0,88 & 0,81 & 0,828 \\
\hline V8 & 0,25 & 0,27 & 0,25 & $\mathrm{X}$ & 0,257 \\
\hline
\end{tabular}

Após obter o volume para cada amostra é possível determinar a porcentagem de cloreto infiltrada no concreto, utilizando a equação (7), apresentados na Tabela 6.

Tabela 6: Porcentagem de cloreto no corpo de prova

\begin{tabular}{|c|c|}
\hline Numeração & {$[\mathbf{C l}] \%$} \\
\hline V1 & 0,0000 \\
\hline V2 & 0,0228 \\
\hline V3 & 0,0215 \\
\hline V4 & 0,0187 \\
\hline V5 & 0,0044 \\
\hline V6 & 0,0032 \\
\hline V7 & 0,0226 \\
\hline V8 & 0,0024 \\
\hline
\end{tabular}

Analisando os valores encontrados na tabela 6, observou-se que as amostras V5, V6 e V8, tiveram uma pequena incidência dos ânions, enquanto os corpos V2, V3, V4 e V7 tiveram uma penetração maior de cloretos.

Os valores encontrados nas amostras de maior concentração seriam preocupantes, visto que em apenas dois anos de exposição observou-se uma concentração entre valores superior a $0,02 \%$. Por esse íon conter um elevado potencial de corrosão das armaduras de concreto armado, pode-se supor que em alguns anos esse teor seria maior do que aceito em algumas normas, de $0,4 \%$ em relação à massa de cimento, ou entre $0,05 \%$ a $0,1 \%$ em relação à massa de concreto. Tal limite se refere aos cloretos totais, pois mesmo que uma parcela se combine as componentes do cimento e forme cloroaluminatos, que ficam incorporados às fases sólidas do cimento hidratado, esses cloretos combinados voltam à dissolução quando sobre efeito de outros processos, como a carbonatação (ANDRADE, 1992). 


\section{CONCLUSÃO}

As medidas de penetração de cloretos identificadas no experimento são coerentes. Apesar de todos os corpos de prova estarem em uma região de agressividade alta: ambiente marinho ou respingo de maré, existem diferenças significativas entre os resultados para diferentes locais de exposição. As maiores concentrações de cloreto foram encontradas nos corpos de prova que estavam expostos a céu aberto, independentemente de estarem armazenados a 50 ou 350 metros do mar. Exceção foi o concreto armazenado na varanda do $5^{\circ}$ andar de um edifício em frente ao mar, que apesar de ser fechado por janelas, as janelas ficam entreabertas durante o ano e totalmente abertas no verão (aproximadamente 3 meses). O concreto exposto a respingos de maré não teve um resultado superior aos demais, armazenados a céu aberto. Isso se explica por que o esse concreto estava entre rochas entre o mar e a areia da praia, e, devido à variação de maré, o concreto ficava submerso em momentos de maré alta, fazendo com que o tempo de exposição aos respingos de maré, fosse reduzido.

Em contrapartida, os três concretos armazenados internos à edificações, dentro de garagens cobertas, apresentaram valores de penetração de cloretos de 5 até 10 vezes menores do que os armazenados a céu aberto. Isso denota que mesmo em uma região supostamente marinha, em edificações em frente ao mar, ou próximas ao mar, existe uma grande diferença em termos de durabilidade de estruturas de concreto armado que são externas ou internas às edificações, no que diz respeito à penetração de íons cloreto. Os corpos de prova utilizados nesta pesquisa continuam armazenados nos mesmo locais para futuras análises ao longo do tempo.

\section{AGRADECIMENTOS}

Agradecemos ao CNPq pela bolsa de estudos concedida para a realização desta pesquisa.

\section{REFERÊNCIAS}

Andrade, C. (1992), "Manual para diagnóstico de obras deterioradas por corrosão de armaduras". São Paulo: PINI.

Associação Brasileira de Normas Técnicas. (2014). NBR 6118: Projeto de estruturas de concreto Procedimento. Rio de Janeiro.

American Society for Testing and Materials. (2018). ASTM C114 - Standard Test Methods for Chemical Analysis of Hydraulic Cement.

Cascudo, O., Helene, P. R. L. (2001), "Resistência à corrosão no concreto dos tipos de armaduras brasileiras para concreto armado". São Paulo, (Boletim Técnico da Escola Politécnica da USP, Departamento de Engenharia de Construção Civil, BT/PCC/272)

Escadeillas, G., Hornain, H. (2014), "A durabilidade do concreto frente a ambientes quimicamente agressivos" in Cascudo, O., Carasek, H. (Eds.), Durabilidade do concreto, bases científicas para a formulação de concretos duráveis de acordo com o ambiente, São Paulo (Brasil), pp 433-508.

Gentil, V. (2007), "Corrosão". 5ª ed. LTC, Rio de Janeiro.

Helene, P. R. L. (1993), "Contribuição ao estudo da corrosão em armaduras de concreto armado”. Tese de Livre docência, Escola Politécnica, Universidade de São Paulo. São Paulo, p. 231.

Medeiros, M. H. F., Borba, A. Y., Filho, J. H., Helene, P. R. L. (2012). "Ensaio de migração de cloretos para concreto: influência do número de fatias extraídas". REM: R.Esc.Minas, Ouro Preto, 65(4), 475481.

Ribeiro, D. V. (2010), "Influência da adição da lama vermelha nas propriedades e na corrosibilidade do concreto armado”. Tese (Doutorado) Programa de PósGraduação em Ciência e Engenharia de Materiais. São Carlos, p. 224. 
Silva, G. A. O. (2017), “Avaliação da durabilidade de concretos contendo agregados reciclados de resíduos de construção civil (RCC)”. Salvador, Universidade Federal da Bahia.

Troian, A. (2010), "Avaliação da durabilidade de concretos produzidos com agregado reciclado de concreto frente à penetração de íons cloretos”. Dissertação (Mestrado) - Programa de Pós- 